\title{
Efeito do tempo de estocagem no comportamento mecânico de mistura asfáltica a frio produzida em usina de pequeno porte
}

\author{
Effect of storage time on mechanical \\ behavior of a cold asphalt mixture \\ produced in a small plant
}

Wallace John Pereira Pedreira ${ }^{1}$, Mario Sergio de Souza Almeida ${ }^{1}$, André Iuri Sena de Carvalho ${ }^{1}$, Francisco Gabriel Santos Silva ${ }^{2}$

\footnotetext{
${ }^{1}$ Universidade Federal do Recôncavo da Bahia, Centro de ciências Exatas e Tecnológicas, Rua Rui Barbosa, 710, Centro, Cruz das Almas, Bahia, Brasil. CEP 44380-00.

${ }^{2}$ Universidade Federal da Bahia, Escola Politécnica, Departamento de Construção e Estruturas, Rua Prof. Aristídes Novis, 2, Federação, Salvador, Bahia, Brasil. CEP 40210-630. e-mail: wallacejppedreira@gmail.com, mario.almeida@ufrb.edu.br, andreyuri_28@hotmail.com,fgabriel.ufba@gmail.com
}

\section{RESUMO}

Parte considerável da malha rodoviária brasileira se concentra em regiões de baixo volume de tráfego, nas quais pavimentar e manter os revestimentos asfálticos existentes em condições mínimas de trafegabilidade é um desafio constante. Neste contexto, os Pré Misturados a Frio (PMF) se destacam como soluções adequadas para suprir a demanda por misturas asfálticas nesses locais. O presente trabalho teve como objetivo avaliar o comportamento mecânico de uma mistura asfáltica fabricada em usina de pequeno porte, ao longo do tempo de estocagem da mistura. Inicialmente foi estabelecido um projeto de dosagem de PMF denso em laboratório para fornecer os parâmetros necessários à produção e controle da mistura fabricada na usina. De posse do projeto foram produzidos cerca de $360 \mathrm{~kg}$ de mistura para realização de testes de estabilidade, fluência, Resistência à Tração por compressão diametral (RT), além da obtenção de parâmetros volumétricos de amostras compactadas após 1, 7, 15, 30 e 60 dias de fabricação. Os resultados demonstraram haver relação entre o tempo de estocagem da mistura e os diferentes parâmetros analisados, ou seja, a perda de umidade no armazenamento proporcionou enrijecimento da mistura, menores densidades das amostras compactadas com consequente aumento dos vazios dos corpos de prova, associado a queda de resistência e deformabilidade.

Palavras-chave: Dosagem Marshall, resistência; emulsão asfáltica.

\begin{abstract}
A considerable part of the Brazilian road network is concentrated in regions with low traffic volumes, in which paving and maintaining existing asphalt coatings in minimum traffic conditions is a constant challenge. In this context, Cold Pre Mixed (CPM) stands out as an adequate solution to supply the demand for asphalt mixtures in these places. The present work aimed to evaluate the mechanical behavior of an asphalt mixture manufactured in a small plant, during the storage time of the mixture. Initially, a dense PMF metering project was established in the laboratory to provide the necessary parameters for the production and control of the mixture manufactured at the plant. In possession of the project, about $360 \mathrm{~kg}$ of mixture were produced to perform stability, flow, tensile strength tests by diametral compression, in addition to obtaining volumetric parameters of compacted samples after 1, 7, 15, 30 and 60 manufacturing days. The results demonstrated a relationship between the storage time of the mixture and the different parameters analyzed, that is, the loss of moisture in the storage provided stiffening of the mixture, lower densities of the compacted samples with a consequent increase in the voids of the specimens, associated with falling resistance and deformability.
\end{abstract}

Keywords: Marshall dosage, resistance; asphalt emulsion. 


\section{INTRODUÇÃO}

O Brasil possui uma malha rodoviária com extensão superior a 1,7 milhões de km, destes cerca de 13\% (230 mil km) são pavimentados majoritariamente com revestimento em misturas asfálticas diversas [2]. O desempenho adequado de revestimentos asfálticos depende, fundamentalmente, da aplicação de procedimentos normatizados associados ao controle das diversas fases, envolvendo o dimensionamento, escolha de materiais, produção das misturas e a execução das camadas asfálticas na pista.

O tipo de solução asfáltica a ser utilizada na pavimentação passa, sobretudo, pelo tipo de tráfego a que os segmentos ficarão expostos ao longo de sua vida útil. O DNIT [16] preconiza desde soluções em misturas a frio, para tráfego considerado pelo departamento como leve, com número de solicitações do eixo padrão de $8,2 \mathrm{t}$ (número $\mathrm{N}$ ) de, no máximo, $5 \times 10^{6}$, até o uso de concreto asfáltico de desempenho mais elevado para tráfego considerado pesado, ou seja, $\mathrm{N}>5 \times 10^{6}$, embora algumas das principais rodovias brasileiras já venham experimentando tráfegos superiores a $10^{8}$. Quando se trata de misturas asfálticas que demandem pequeno esforço para confecção e possibilidade de armazenamento, os Pré Misturados a Frio (PMF) se posicionam como opção adequada quando comparados com as misturas a quente, as quais demandam rigoroso controle de produção, elevado consumo energia para aquecimento do Cimento Asfáltico de Petróleo (CAP) e dos agregados $[25,32]$ e, principalmente, aplicação imediata da produção.

A Associação Brasileira das Empresas Distribuidoras de Asfalto (ABEDA) [1] classifica granulometricamente os PMF em abertos, semidensos e densos, recomendando o uso de emulsões asfálticas de Ruptura Média (RM), para as misturas abertas, e de Ruptura Lenta (RL), para os outros dois tipos. Esta recomendação é referendada pela especificação de serviço DNIT [14]. Ainda de acordo com ABEDA [1], a utilização do PMF é recomendada para rodovias de tráfego considerado leve, ressaltando como uma das principais características do produto a possibilidade de estocagem, com período máximo de armazenamento, em função do tipo de emulsão asfáltica utilizada, podendo variar entre 7 dias (RL) e 30 dias (RM).

Para RENDELIUS et al. [26], nas misturas asfálticas do tipo PMF a taxa de ruptura da emulsão deve ser lenta o suficiente para que a mistura seja produzida, estocada, transportada para o local e aplicado antes de seu enrijecimento. A emulsão deve começar o processo de ruptura durante a compactação e continuar a romper rapidamente no local de aplicação, uma vez concluída a compactação. No entanto, pode ser difícil prever a taxa de ruptura de uma emulsão, pois é muito dependente do tipo de agregado e graduação da mistura escolhida. Esta taxa é mais provavelmente dependente da natureza da superfície agregado, tal como a área superficial específica combinada com tipo mineral. Para os autores um ponto crítico para a produção de PMF é a necessidade de gerenciar o excesso de água da emulsão, pois um elevado volume de vazios pode reduzir a expectativa de vida da mistura no campo. Entretanto, os autores avaliaram trechos experimentais com revestimento a frio por quinze anos e classificaram as vias como em excelente estado de conservação, onde análises do ligante asfáltico extraído revelaram seu baixo nível de envelhecimento, apesar do volume de vazios da mistura estar entre $10 \%$ e $12 \%$.

Diferentes estudos buscaram compreender o efeito da umidade na qualidade do PMF [27, 17, 34]. LIU et al. [24] avaliaram a influência da umidade do agregado no comportamento mecânico de uma mistura asfalto/resina a frio. Os resultados dos ensaios mostraram que a aderência entre o ligante asfáltico e os agregados é enfraquecida pela umidade dos agregados, afetando negativamente as propriedades mecânicas da mistura. Os autores introduziram cal na mistura e concluíram que o aditivo funciona como atenuador dos efeitos negativos produzidos pela umidade. A adesividade do ligante ao agregado está diretamente relacionada à diferença de polaridade destes materiais. Quando a adesividade é baixa, as misturas asfálticas apresentam rápida degradação, tendo em vista o descolamento da película de ligante aderida ao agregado [30]. Quando a interação entre agregado e ligante é insatisfatória, a falha de adesividade é acelerada quando o pavimento é submetido ao contato com a água. Agregados da região nordeste do Brasil, por exemplo, apresentam polaridade semelhante ao ligante, logo, o uso de aditivos melhoradores de adesividade torna-se imprescindível [29].

SENA NETO et al. [31] avaliaram propriedades Marshall de misturas asfálticas a frio contendo diferentes teores de emulsão asfáltica e resíduo de construção e demolição (RCD). Os resultados indicaram maior estabilidade com um menor volume de vazios e maior densidade aparente, com percentuais de emulsão asfáltica testados no teor de projeto, em função do eficiente empacotamento dos grãos e, consequentemente, da produção de matrizes mais densas. GAO et al. [20] avaliaram, utilizando tomografia computadorizada por raios-X, a influência de diferentes métodos de compactação no volume de vazios de misturas asfálticas recicladas a frio com uso de emulsão asfáltica de ruptura lenta como aditivo. Os resultados indicaram que os volumes de vazios em diferentes profundidades das amostras variaram em função do método de compactação utilizado, sendo que a compactação de carga estática tendeu a produzir volumes de vazios menores, o compactador giratório, volumes de vazios intermediários, enquanto a compactação Marshall convencional ofertou 
os maiores volumes de vazios das misturas testadas.

Estudos recentes [18, 23] avaliaram o uso de diferentes tipos de emulsões e outros aditivos em misturas asfálticas a frio, recicladas, produzidas com diferentes teores de RAP (Reclaimed Asphalt Pavement), que é o material asfáltico envelhecido extraído da pista pelo processo de fresagem do revestimento. Os testes de laboratório mostram que a presença destes aditivos influencia no comportamento mecânico das misturas [22, 19]. Entretanto, UNGER FILHO et al. [33] estudaram misturas asfálticas recicladas a frio, compostas de $100 \%$ de RAP, com uso de emulsão asfáltica de reciclagem, para utilização como camada de base de pavimento. O objetivo foi analisar em laboratório e campo a influência do tempo de estocagem de 7, 14 e 28 dias da mistura produzida, antes da compactação, e o tempo de cura de 1, 3, 7, 26 e 56 dias, após compactação, no comportamento mecânico da mistura reciclada. Os autores concluíram, a partir de ensaios de Módulo de Resiliência (MR) e Resistência a Tração na compressão diametral (RT), que o tempo de armazenamento melhorou, para curtos períodos de cura, as propriedades mecânicas das misturas recicladas a frio, provavelmente, segundo eles, devido à interação entre o asfalto envelhecido e o agente de reciclagem de asfalto emulsionado na condição solta das misturas. Com aumento do tempo de cura, esse aumento inicial mostrou-se insignificante.

De acordo com DIAZ [4], parte dos testes para caracterização do PMF se concentra na trabalhabilidade da mistura em vez de seu desempenho, principalmente por estes materiais serem muitas vezes utilizados como uma solução temporária. No entanto, estudos recentes vêm demonstrando o potencial deste tipo de mistura para ser utilizada como uma solução permanente. DAY et al. [5] apresentam resultados de dez anos de experiências de campo e laboratório na Europa, os quais demonstram sucesso da utilização de misturas a frio em pavimentos de regiões de tráfego elevado no Reino Unido. Ainda segundo os autores, o sucesso no controle laboratorial implementado, em conjunto com o desenvolvimento contínuo das especificações, lançou as bases para a adoção mais ampla de soluções em PMF em pavimentos no País.

O presente trabalho tem como objetivo avaliar a influência do tempo de estocagem no comportamento mecânico de um PMF produzido em uma usina de pequeno porte, através de ensaios de estabilidade, fluência, volume de vazios, resistência à tração por compressão diametral.

\section{MATERIAIS E MÉTODOS}

O programa experimental desenvolvido foi dividido em três etapas principais. Na primeira delas foi elaborada a dosagem de uma mistura asfáltica do tipo Pré Misturado a Fio (PMF), composta pelo proporcionamento dos agregados, caracterização da emulsão asfáltica e determinação do teor de projeto de ligante asfáltico da mistura. A segunda etapa constou da produção da mistura asfáltica dosada, contemplando o recebimento e controle dos agregados e a usinagem propriamente dita da mistura. Por fim, na última etapa, executou-se o controle de qualidade da mistura usinada, envolvendo armazenamento em tempos variados, seguido da determinação dos parâmetros volumétricos, de resistência e deformabilidade da mistura ao longo do tempo.

\subsection{Projeto de dosagem do PMF}

\subsubsection{Caracterização dos agregados}

A dosagem do PMF foi realizada de acordo com o método do DNER [11]. A primeira tarefa foi definir agregados para o projeto da mistura, em função de suas granulometrias, para atendimento a uma das faixas granulométricas definidas pela especificação de serviço do DNIT [14], utilizando-se, para isso, dois agregados, a brita 5/8", como agregado graúdo, e o pó de pedra, como agregado miúdo, ambos oriundos de uma pedreira comercial, localizada na cidade de Muritiba, estado da Bahia. A escolha desses dois agregados se baseou no propósito de atender a faixa granulométrica $\mathrm{D}$, a qual é a mais densa da referida especificação [14]. A opção pela faixa D se justifica por esta ser uma das mais utilizadas para revestimento em PMF, dentre as previstas na especificação [14]. Na sequência foi realizada a análise granulométrica por peneiramento destes dois agregados, conforme o método de ensaio DNER [9]. Estes ensaios foram realizados em triplicata, adotandose o valor passante médio como característico de cada peneira utilizada. A Tabela 1 apresenta a granulometria dos agregados utilizados no traço do PMF.

Posteriormente, procedeu-se a realização dos ensaios para determinação da densidade e absorção do agregado graúdo [8], determinação da densidade real do agregado miúdo [10] e equivalente de areia para o pó de pedra [7]. A Tabela 2 sintetiza os resultados obtidos destes ensaios. 
Tabela 1: Granulometria dos agregados utilizados na dosagem.

\begin{tabular}{cccc}
\hline & PENEIRAS & BRITA 5/8" & PÓ DE PEDRA \\
\hline \multirow{2}{*}{ Nomenclatura } & $\begin{array}{c}\text { Abertura } \\
(\mathrm{mm})\end{array}$ & $\begin{array}{c}\% \\
\text { passante }\end{array}$ \\
\hline 1" $^{\prime \prime}$ & 25,4 & 100 & 100 \\
$1 / 2 "$ & 19,0 & 100 & 100 \\
$3 / 8 "$ & 12,7 & 91,72 & 100 \\
$\# 4$ & 9,5 & 40,26 & 99,79 \\
$\# 10$ & 4,8 & 2,93 & 95,77 \\
$\# 200$ & 2,0 & 1,68 & 59,27 \\
\end{tabular}

Tabela 2: Densidade, absorção e equivalente de areia dos agregados.

\begin{tabular}{ccc}
\hline ENSAIO & BRITA 5/8" & PÓ DE PEDRA \\
\hline Densidade aparente & 2.705 & - \\
Densidade real & 2.724 & 2,857 \\
Absorção $(\%)$ & 0,25 & - \\
Equivalente de areia $(\%)$ & - & 63,72 \\
\hline
\end{tabular}

\subsubsection{Caracterização da emulsão asfáltica}

A emulsão asfáltica utilizada nesta pesquisa foi do tipo RL-1C, produzida em um lote específico pela Empresa BRASQUÍMICA S. A para realização do presente estudo. A opção por utilizar este tipo de emulsão, que é de ruptura lenta, está relacionada a faixa granulométrica escolhida para a mistura (densa), conforme a especificação DNIT [14]. A especificação de materiais DNIT [15] define os ensaios de caracterização que devem ser realizados com a emulsão, estabelecendo os limites a serem satisfeitos pelo produto. Os resultados desses ensaios de caracterização da emulsão asfáltica, realizados pela empresa fabricante e fornecidos junto com o produto, estão apresentados na Tabela 3.

Tabela 3: Caracterização da emulsão asfáltica.

\begin{tabular}{cccc}
\hline CARACTERístiCA & EXIGÊNCIA & RESULTADOS & MÉtODO DE ENSAIO \\
\hline Viscosidade Saybolt Furol a $25^{\circ} \mathrm{C}$ & Máx $90 \mathrm{~s}$ & 18 & NBR 14491 \\
Sedimentação após 5 dias, & Máx $5(\% \mathrm{~m} / \mathrm{m})$ & 2,4 & NBR 6570 \\
Peneiração $(0,84 \mathrm{~mm})$ & Máx $0,1(\% \mathrm{~m} / \mathrm{m})$ & 0,01 & NBR 14393 \\
Carga de partícula $(+/-)$ & Positiva & Positiva & NBR 6567 \\
pH & Máx 6,5 & 2,6 & NBR 6299 \\
Resíduo de asfalto & Mín $60(\% \mathrm{~m} / \mathrm{m})$ & 60,2 & NBR 14376 \\
\hline
\end{tabular}

\subsubsection{Determinação do teor de ligante asfáltico de projeto do PMF}

De posse da granulometria dos agregados foi possível definir o percentual de cada um na mistura, para atendimento a faixa D do PMF. A melhor combinação entre os dois agregados correspondeu a $65 \%$ de brita $5 / 8$ " e 35\% de pó de pedra. A composição granulométrica da mistura de agregados e os limites da faixa D [14], estão apresentados na Tabela 4. A composição granulométrica da mistura de agregados está detalhada na Figura 1, incluindo a tolerância por peneira estabelecida pela mesma especificação.

O projeto de dosagem foi elaborado para as duas energias de compactação previstas no método de ensaio DNER [11], ou seja, 50 e 75 golpes. Para a determinação do teor de ligante asfáltico de projeto da mistura foram testados os teores de 4,0; 4,5; 5,0; 5,5 e 6,0\% de CAP residual, que correspondem, respectivamente, a $6,7 \%, 7,5 \%, 8,3 \%, 9,2 \%$ e $10 \%$ de emulsão asfáltica, considerando o resíduo de asfalto indicado na Tabela 3. Logo após foram confeccionados três corpos de prova (CP) para cada teor e energia de compactação, seguindo a metodologia Marshall definida pelo método de ensaio [11]. A massa de mistura preparada para cada 
CP foi de $1200 \mathrm{~g}$.

Posteriormente foram determinadas as medidas dos corpos de prova para cálculo dos parâmetros volumétricos da mistura. É importante destacar que, em função das características do PMF dosado, houve a necessidade, conforme o método de ensaio DNER [12], do uso de fita adesiva e parafina para a pesagem submersa dos $\mathrm{CP}$ pelo fato da mistura apresentar volume de vazios superior a $10 \%$.

Tabela 4: Composição granulométrica da mistura de agregados da dosagem do PMF.

\begin{tabular}{ccccc}
\hline & PENEIRAS & & MISTURA & \multicolumn{2}{c}{ DNIT [14] - FAIXA D } \\
\hline \multirow{2}{*}{ Nome } & $\begin{array}{c}\text { Abertura } \\
(\mathrm{mm})\end{array}$ & $\begin{array}{c}\% \\
\text { passante }\end{array}$ & $\begin{array}{c}\text { Limite inferior } \\
\text { \% passante }\end{array}$ & $\begin{array}{c}\text { Limite superior } \\
\% \text { passante }\end{array}$ \\
\hline $1^{\prime \prime}$ & 25,4 & 100 & 100 & 100 \\
$3 / 4^{\prime \prime}$ & 19,0 & 100 & 100 & 100 \\
$1 / 2 "$ & 12,7 & 95 & 95 & 100 \\
$3 / 8^{\prime \prime}$ & 9,5 & 61 & 45 & 80 \\
$\# 4$ & 4,8 & 35 & 25 & 45 \\
$\# 10$ & 2,0 & 22 & 15 & 30 \\
$\# 200$ & 0,075 & 5 & 0 & 8 \\
\hline
\end{tabular}

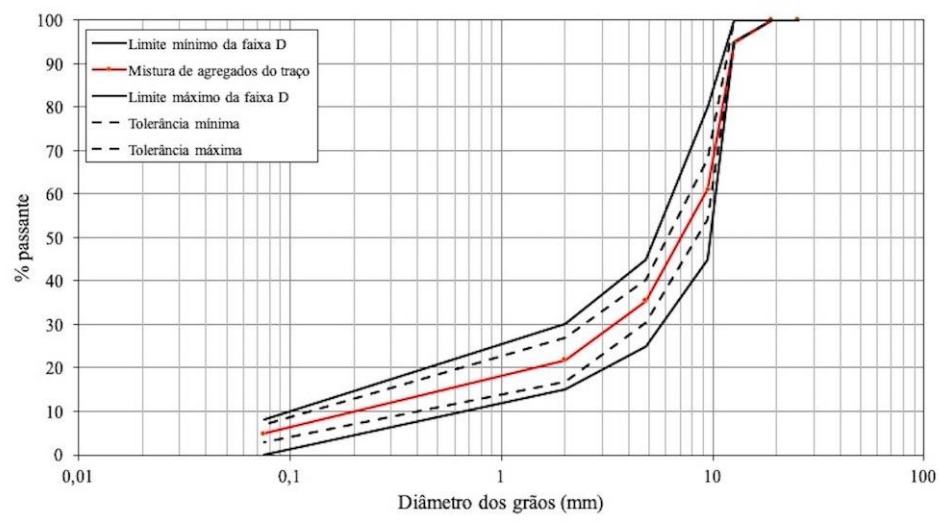

Figura 1: Granulometria da mistura de agregados da dosagem do PMF.

Os CP foram ensaiados de acordo com o método de ensaio DNER [11], na prensa para determinação da estabilidade Marshall e fluência. O volume de vazios (Vv) foi calculado com a composição de agregados, porcentagem de CAP residual e suas respectivas densidades reais apresentadas na Tabela 2. Os resultados médios de cada parâmetro avaliado foram plotados graficamente, em função do teor de CAP residual, conforme apresentado na Figura 2.

A metodologia Marshall, adaptada para PMF [11], apresenta exigências de estabilidade mínima de $150 \mathrm{kgf}$, para 50 golpes, e $250 \mathrm{kgf}$, para 75 golpes, fluência entre $2 \mathrm{~mm}$ e $4,5 \mathrm{~mm}$ e volume de vazios entre $5 \%$ e $30 \%$ para determinação do teor de CAP residual de projeto da mistura. Assim, de acordo com sugestão de SANTANA [28], dentre os teores testados o ideal deverá ser aquele que obtiver a maior massa específica aparente, ou seja, o menor volume de vazios. Dessa forma, considerando-se os resultados de estabilidade, fluência e Vv apresentados na Figura 2, dentre os teores testados, apenas 4\%, 4,5\% e 5\% atenderam aos limites exigidos pelo método DNER [11] para os três atributos. Dentre estes o teor de 5\% foi o que obteve a maior massa específica aparente. Entretanto, entre 4,5\% e 5\% houve queda na estabilidade para as duas energias, motivo pelo qual optou-se pela média entre estes dois valores. Com essa metodologia adotada, determinou-se o teor de 4,8\% como o de projeto para 50 e 75 golpes, que equivale a $8 \%$ de emulsão asfáltica, sendo o resíduo de asfalto na emulsão de $60 \%$, conforme a Tabela 3. O traço de projeto, considerando o ligante asfáltico, ficou definido com 4,8\% de CAP residual ( $8 \%$ de emulsão), $61,88 \%$ de brita $5 / 8$ " e 33,32\% de pó de pedra. 


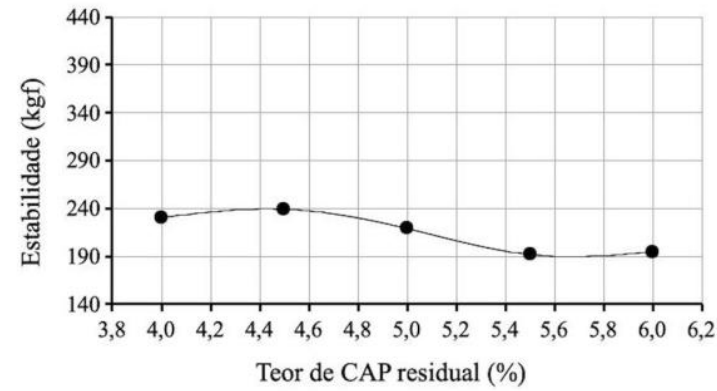

(a) Estabilidade - 50 golpes

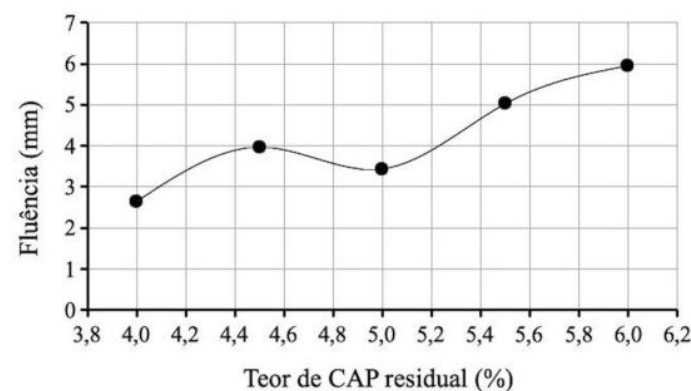

(b) Fluência Marshall - 50 golpes

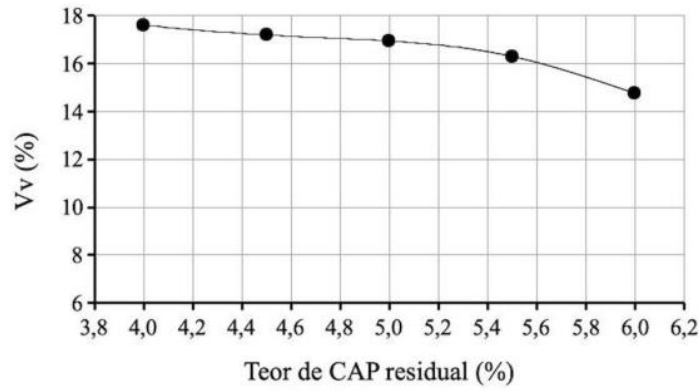

(c) Volume de vazios - 50 golpes

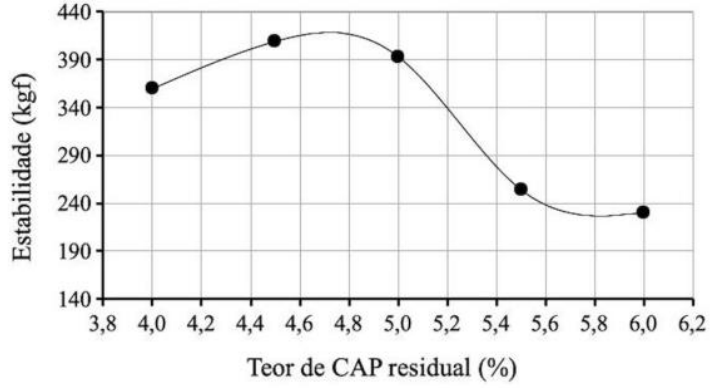

(d) Estabilidade - 75 golpes

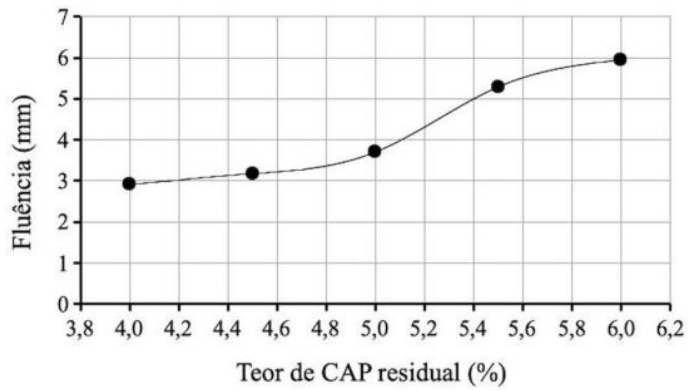

(e) Fluência Marshall - 75 golpes

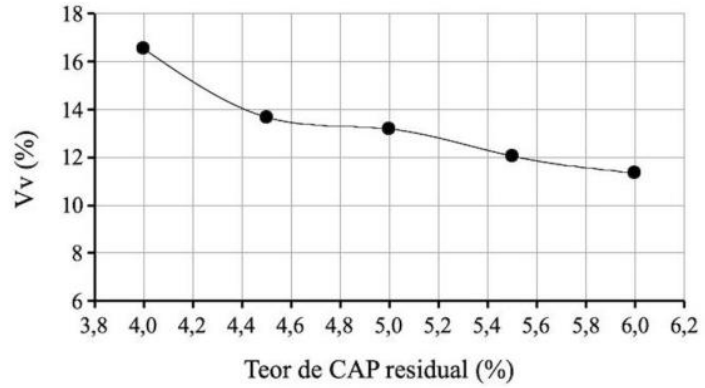

(f) Volume de vazios - 75 golpes

Figura 2: Resultados da dosagem do PMF.

Para confirmação do teor de ligante de projeto previamente determinado $(4,8 \%$ de CAP residual ou $8 \%$ de emulsão asfáltica) foram moldados seis novos corpos de prova, sendo três para cada energia de compactação, para confirmação dos parâmetros de controle listados anteriormente, ou seja, estabilidade, fluência e Vv. Embora não previsto na especificação de serviço DNIT [14], outras seis amostras foram preparadas no teor de projeto para realização de ensaios de RT, de acordo com o método de ensaio DNIT [13], com o objetivo de qualificar o controle de qualidade futuro da mistura produzida na usina e testada ao longo do tempo de estocagem. Na Tabela 5 são apresentados os resultados obtidos da caracterização da mistura no teor de projeto determinado, permitindo observar que com a quantidade de emulsão asfáltica determinada (ou CAP residual) atendeu-se todas as exigências da especificação de serviço DNIT [14], para as duas energias testadas. 
Tabela 5: Caracterização do PMF no teor de projeto da mistura.

\begin{tabular}{cccc}
\hline \multirow{2}{*}{ No DE GOLPES } & PARÂMETROS DE & RESULTADOS NO TEOR & EXIGÊNCIAS \\
CONTROLE & DE PROJETO & DNIT [14] \\
\hline \multirow{2}{*}{50} & Estabilidade (kgf) & 235,0 & $\geq 150$ \\
& Fluência (mm) & 4,0 & 2 a 4,5 \\
& Volume de vazios (\%) & 17,5 & 5 a 30 \\
& RT (MPa) & 0,05 & - \\
\hline \multirow{2}{*}{75} & Estabilidade (kgf) & 335 & $\geq 250$ \\
& Fluência (mm) & 3,4 & 2 a 4,5 \\
& Volume de vazios (\%) & 15,6 & 5 a 30 \\
& RT (MPa) & 0,08 & - \\
\hline
\end{tabular}

\subsection{Produção da mistura asfáltica em uma usina de pequeno porte}

O traço projetado da mistura foi produzido na usina de pequeno porte da Universidade Federal do Recôncavo da Bahia, marca CONISHI, modelo UP $1.5^{\circledR}$, com capacidade de produção de $1,5 \mathrm{t} / \mathrm{h}$. Esse equipamento prevê o abastecimento manual dos agregados e emulsão definidos no projeto da mistura. A Figura 3 apresenta o sistema empregado no processo produtivo, composto pela referida usina e contêiner metálico para recebimento da mistura asfáltica pronta.

A produção consistiu, conforme orientações do manual do fabricante, em abastecer o equipamento inicialmente com o agregado graúdo. Dessa forma, foram inseridos no equipamento três latas de agregado graúdo, correspondendo a 74,5 $\mathrm{kg}(61,88 \%)$, com o equipamento ligado e com seu dispositivo de controle acionado para esquerda. Em seguida adicionou-se cinco litros de água, de forma a facilitar a mistura com a emulsão, visto que o agregado utilizado estava seco. Logo após foi adicionado 9,6 litros de emulsão (8\%), correspondendo, aproximadamente, a 4,8\% de CAP residual (teor de projeto) e, por fim, duas latas de agregado miúdo, equivalentes a $40 \mathrm{~kg}(33,32 \%)$. Importante destacar que foi realizada a homogeneização da emulsão que estava armazenada num tonel de 2001 antes de adicioná-la à mistura, agitando-a cuidadosamente a fim de evitar a decantação da fase asfáltica no fundo do recipiente. Em cada processo desse descrito foi possível usinar cerca de $120 \mathrm{~kg}$ de PMF, totalizando $360 \mathrm{~kg}$ em três usinagens.

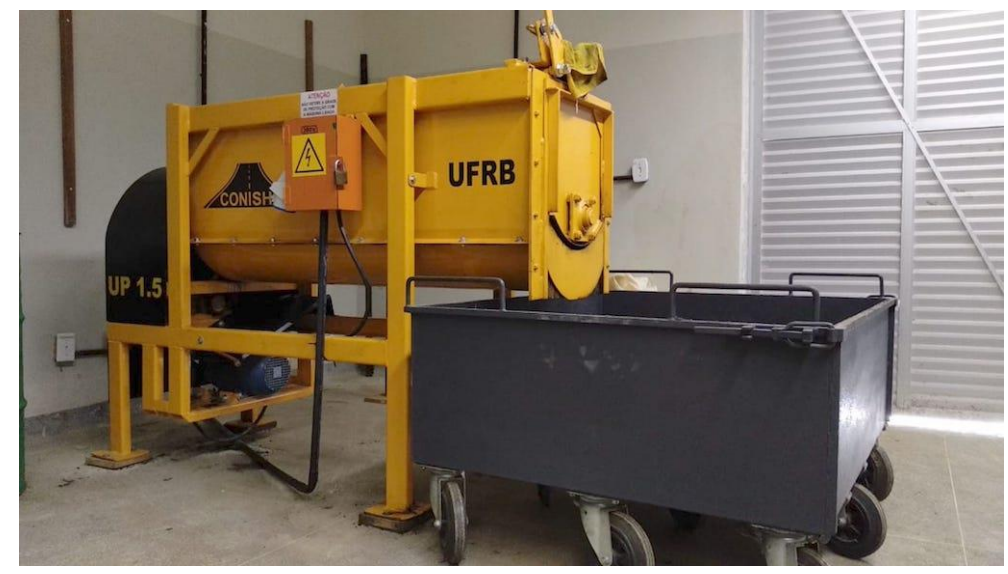

Figura 3: Usina de PMF.

\subsection{Controle de qualidade da mistura produzida}

A mistura usinada saiu do equipamento diretamente para o contêiner metálico, com capacidade de, aproximadamente, $700 \mathrm{~kg}$ de PMF. Logo após o fim da usinagem todo material produzido foi homogeneizado no próprio contêiner para garantir uniformidade granulométrica da mistura, minimizando o risco de ocorrência de segregação. O PMF permaneceu nesse contêiner pelos três primeiros dias dentro do galpão de produção, devidamente coberto por lona plástica. Após um dia de produzido foram amostrados $15 \mathrm{~kg}$ da mistura para a realização dos ensaios da rotina experimental definida, ou seja, estabilidade, fluência, Vv e RT. Após três dias, com a saída do excesso de água da produção do PMF, foi realizado o procedimento de amostragem e acondicionamento de toda a produção remanescente em sacolas plásticas, contendo cerca de $15 \mathrm{~kg}$ cada, sen- 
do estas armazenadas em outro contêiner plástico, de modo a minimizar as perdas de umidade ao longo do tempo de estocagem. Cada quantidade amostrada $(15 \mathrm{~kg})$ foi suficiente para a continuação da rotina experimental em diferentes idades de armazenamento da mistura, ou seja, 1, 7, 15, 30 e 60 dias.

Com o objetivo de avaliar possíveis influências da granulometria e teor de CAP residual em cada etapa de testagem, foram realizados, ainda, a extração do ligante asfáltico e posterior granulometria. Estes ensaios serviram para verificar a qualidade da mistura produzida em relação às características do projeto da mistura elaborado. A determinação do teor de CAP residual contido na mistura, para cada idade testada, teve como procedimento obter de cada corpo de prova ensaiado na metodologia Marshall, para cada energia (50 e 75 golpes), cerca de $400 \mathrm{~g}$, ou seja, 1/3 da massa de cada CP, para que fosse ensaiada no equipamento Rotarex, conforme o método de ensaio do DNER [6]. Finalmente, os agregados obtidos em cada procedimento de extração foram colocados para secagem em estufa, à temperatura entre $80^{\circ} \mathrm{C}$ e $100^{\circ} \mathrm{C}$, até constância da massa. Com os agregados secos, foram realizados ensaios de granulometria de acordo com o respectivo método de ensaio [9].

\section{RESULTADOS E DISCUSSÕES}

\subsection{Comportamento mecânico da mistura produzida}

A Tabela 6 apresenta os resultados médios de estabilidade, fluência, Vv e RT para as diferentes idades de estocagem do PMF analisadas e energias de compactação de 50 e 75 golpes.

Os resultados dos quatro parâmetros avaliados e apresentados na Tabela 6, para as duas energias de compactação, indicam haver correlação entre o tempo de armazenamento da mistura produzida e os respectivos parâmetros encontrados nos ensaios realizados. A perda de umidade provoca uma tendência de enrijecimento do Pré Misturado a Frio, dificultando, com o passar do tempo, a compactação nas duas energias testadas, influenciando no comportamento mecânico da mistura produzida.

Vale destacar que nas Figuras 4 a 7 foram introduzidas curvas de ajuste matemático (logarítmica) e seus respectivos coeficientes de correlação $\left(\mathrm{R}^{2}\right)$, de forma a visualizar a tendência de cada parâmetro analisado em temos de variação quantitativa ao longo do tempo.

Tabela 6: Parâmetros de controle de qualidade nas diferentes idades da mistura produzida.

\begin{tabular}{|c|c|c|c|c|c|}
\hline № DE GOLPES & $\begin{array}{l}\text { IDADE } \\
\text { (dias) } \\
\end{array}$ & $\begin{array}{c}\text { ESTABILIDADE } \\
(\mathrm{kgf}) \\
\end{array}$ & $\begin{array}{c}\text { FLUÊNCIA } \\
(\mathrm{mm})\end{array}$ & $\begin{array}{l}\text { VV } \\
(\%)\end{array}$ & $\begin{array}{c}\mathbf{R T} \\
(\mathrm{MPa}) \\
\end{array}$ \\
\hline \multirow{5}{*}{50} & 1 & 319 & - & 9,2 & 0,057 \\
\hline & 7 & 178 & 3,70 & 13,3 & 0,042 \\
\hline & 15 & 149 & 2,88 & 15,1 & 0,033 \\
\hline & 30 & 106 & 1,02 & 15,0 & 0,033 \\
\hline & 60 & 89 & 1,52 & 16,3 & 0,030 \\
\hline \multirow{5}{*}{75} & 1 & 381 & 3,73 & 9,6 & 0,102 \\
\hline & 7 & 166 & 2,37 & 13,4 & 0,067 \\
\hline & 15 & 177 & 1,50 & 12,9 & 0,048 \\
\hline & 30 & 161 & 1,50 & 12,4 & 0,048 \\
\hline & 60 & 127 & 1,19 & 14,5 & 0,053 \\
\hline
\end{tabular}

\subsubsection{Estabilidade Marshall}

A variação da estabilidade Marshall, em função do tempo de estocagem do PMF, está apresentada na Figura 4. $\mathrm{O}$ ajuste dos pontos da Figura 4 auxilia na demonstração de que a estabilidade tende a decrescer com o aumento do tempo de estocagem do PMF. Enquanto com 1 dia de armazenamento da mistura os valores medidos para 50 golpes e 75 golpes foram superiores aos da especificação de serviço [14], correspondendo à $113 \%$ e $52 \%$ de aumento, respectivamente, para 60 dias os valores de estabilidade ficaram abaixo, correspondendo a $59 \%$ e $51 \%$ dessa mesma referência.

Ressaltando que para as energias de compactação de 50 e 75 golpes os limites mínimos estabelecidos de estabilidade pela especificação DNIT [14] são de 150 kgf, para 50 golpes, e 250 kgf, para 75 golpes, os 
testes realizados demonstram que a mistura produzida, conforme foi armazenada, enquadrou-se nessas exigências até as idades de estocagem de, aproximadamente, 15 dias para 50 golpes e 5 dias para 75 golpes, estimados utilizando as equações de ajuste com valores de $\mathrm{R}^{2}$ entre 0,98 e 0,85 para as duas energias, com tempos de estocagem diferentes do preconizado pela ABEDA [1] para misturas produzidas com emulsão de ruptura lenta. A partir desses tempos de estocagem estimados os valores de estabilidade de ambas energias continuaram caindo, tendendo a valores entre $70 \mathrm{kgf}$ e $100 \mathrm{kgf}$ com 60 dias.

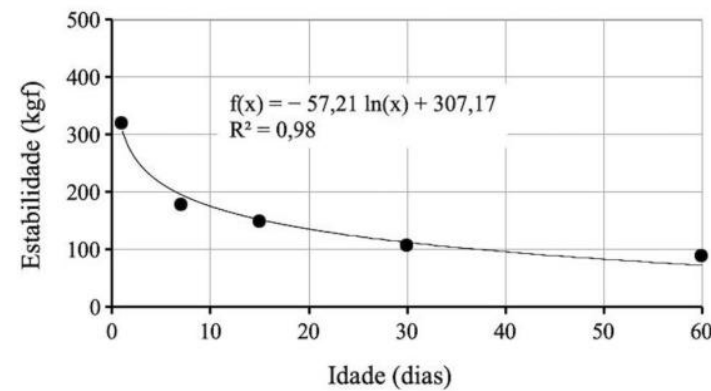

(a) 50 golpes

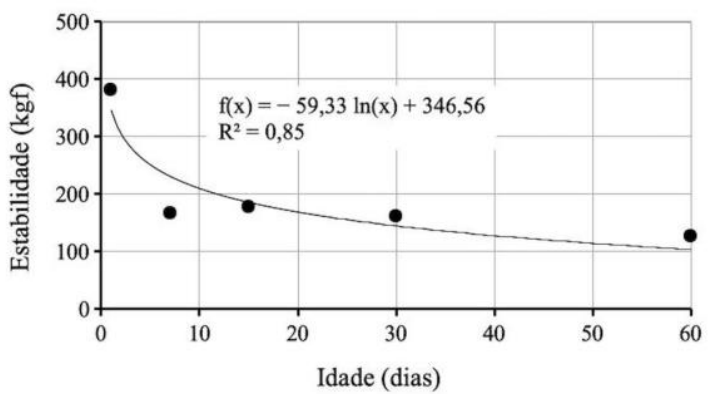

(b) 75 golpes

Figura 4: Variação da estabilidade do PMF em função do tempo de estocagem.

\subsubsection{Resistência à Tração por compressão diametral (RT)}

O comportamento da mistura em termos de RT ao longo do tempo de estocagem apresentou ajustes com coeficiente de correlação $\left(\mathrm{R}^{2}\right)$ de 0,95 e 0,84 para 50 e 75 golpes, respectivamente, conforme a Figura 5.

Como não há exigência de limites para RT na especificação de serviço para PMF [14], mesmo com a importância desse parâmetro para análise da resistência de misturas asfálticas destacada por BERNUCCI $e t$ al. [3], a referência utilizada no presente trabalho para a mistura produzida foram os valores obtidos na aferição do teor de projeto. Portanto, a variação de RT observada partiu de $14 \%$ e $28 \%$ acima dos valores obtidos na dosagem, com idade de 1 dia de estocagem, para 50 e 75 golpes, respectivamente, para $40 \%$ e $34 \%$ abaixo com 60 dias. Ou seja, é importante observar que a redução percentual da RT ao longo do tempo foi sensivelmente inferior a que ocorreu com a estabilidade no mesmo período. Enquanto na curva de estabilidade tendeu a valores entre $70 \mathrm{kgf}$ e $100 \mathrm{kgf}$ com 60 dias de estocagem, os quais representam cerca de $30 \%$ em relação aos resultados da dosagem, a RT tendeu, na mesma idade, a valores entre 0,027 MPa e 0,043 MPa, ou seja, aproximadamente $54 \%$ em relação aos resultados obtidos para a mesma referência (Tabela 5). Cabe ainda destacar que a evolução da RT em função do tempo de estocagem no presente estudo foi diferente do observado por UNGER FILHO et al. [33] para misturas recicladas avaliadas a curto período de cura.
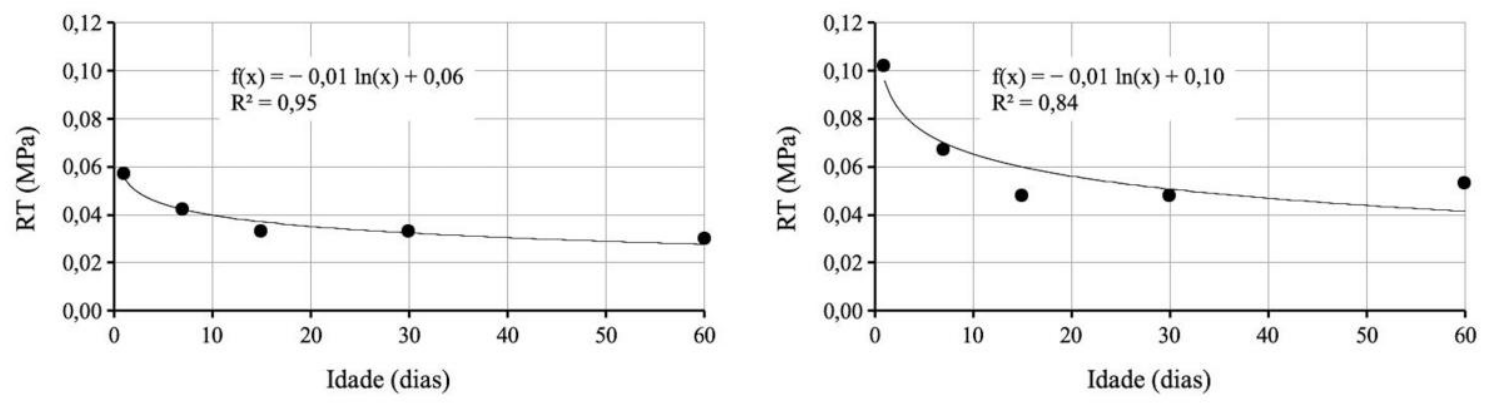

(a) 50 golpes

(b) 75 golpes

Figura 5: Variação da RT do PMF em função do tempo de estocagem.

\subsubsection{Fluência e Volume de vazios}

Os resultados de fluência e volume de vazios, para as duas energias testadas, estão apresentados na Figura 6.

A variação observada na estabilidade e RT do PMF ao longo do tempo (Figuras 4 e 5, respectivamen- 
te), pode ser também visualizada na Figura 6 para o Vv e fluência. Em relação ao volume de vazios, como o DNIT [14] estabelece uma faixa muito larga de valores aceitáveis para ambas as energias de compactação, de $5 \%$ a $30 \%$, todos os resultados obtidos, independentemente da idade ensaiada, atenderam a esse critério, com coeficientes de correlação de 0,96 e 0,75 , respectivamente, para 50 e 75 golpes.

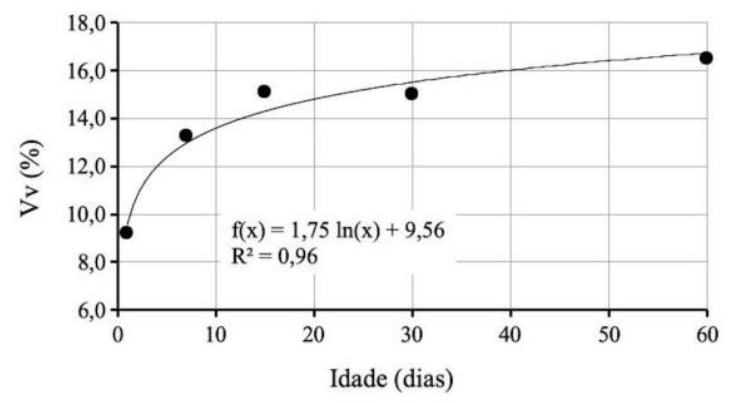

(a) Volume de vazios - 50 golpes

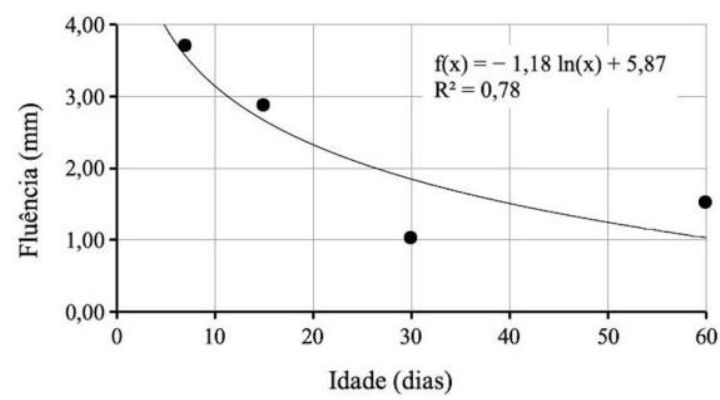

(c) Fluência - 50 golpes

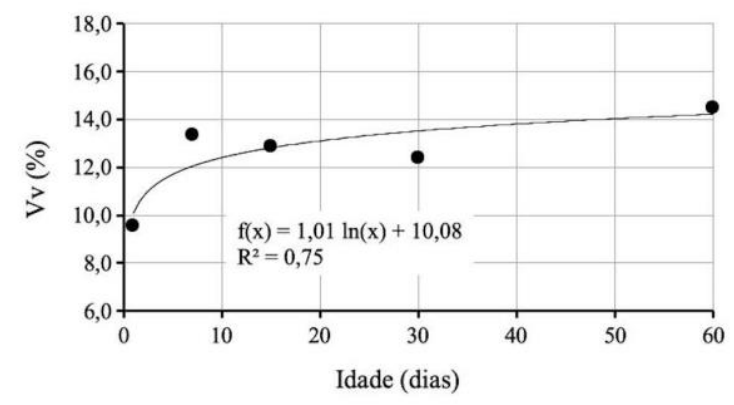

(b) Volume de vazios - 75 golpes

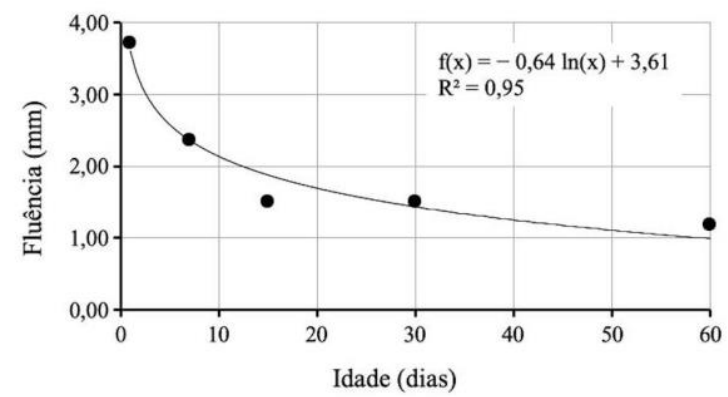

(d) Fluência - 75 golpes

Figura 6: Variação do volume de vazios e fluência do PMF em função do tempo de estocagem.

Quanto a fluência, com a utilização das equações de ajuste da Figura 6 (c e d) é possível visualizar a queda deste parâmetro para as duas energias e estimar que o tempo em que o limite mínimo de $2 \mathrm{~mm}$, estabelecido pela especificação de serviço DNIT [14], será alcançado tende a 26 dias de estocagem, para 50 golpes $\left(\mathrm{R}^{2}=0,78\right)$, e 12 dias para 75 golpes $\left(\mathrm{R}^{2}=0,95\right)$, aproximadamente. Esses tempos definidos são superiores aos anteriormente estabelecidos com base nos resultados de estabilidade. Portanto, o critério da resistência mostra-se mais restritivo quanto ao tempo máximo de armazenamento da mistura, entre as exigências contidas na especificação [14].

Para auxiliar na análise do comportamento mecânico da mistura é importante conhecer a variação da densidade aparente das amostras compactadas e testadas (Dap) em função do tempo de estocagem, de acordo com a Figura 7.

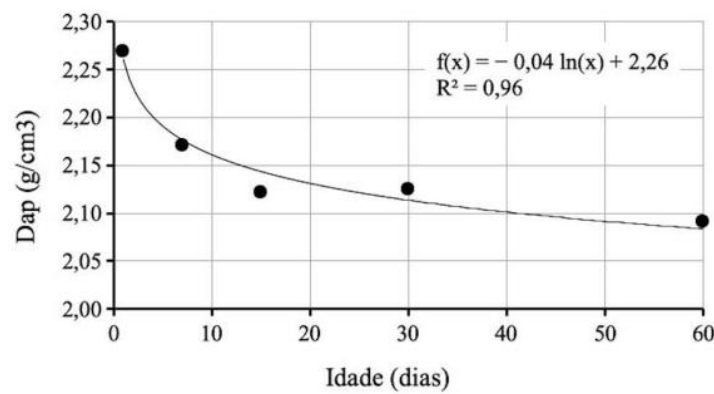

(a) 50 golpes

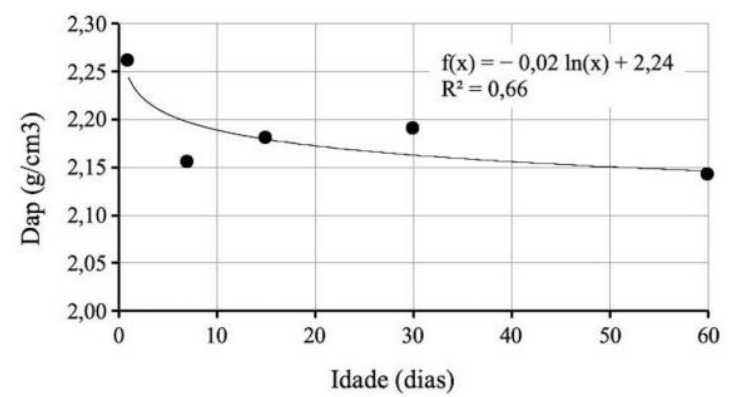

(b) 75 golpes

Figura 7: Variação da densidade aparente das amostras compactadas de PMF em função do tempo de estocagem. 
É possível observar que os resultados obtidos para as quatro variáveis avaliadas indicam que a perda de umidade no processo de estocagem a que a mistura foi submetida ao longo do tempo de armazenamento possui relação com a crescente elevação na dificuldade de densificação do material, na operação de compactação a qual as amostras foram submetidas, comprovada pela redução da densidade aparente média (Dap) ao longo do tempo.

\subsection{Controle do teor de ligante e granulometria da mistura produzida}

Os resultados médios dos ensaios de extração de CAP residual, bem como da granulometria da mistura, para as diferentes idades testadas, estão apresentados nas Tabelas 7 e 8 . Na Tabela 7 estão apresentados, adicionalmente, os respetivos valores de média, Desvio Padrão (DP) e Coeficiente de Variação (CV) calculados com base nos resultados obtidos para as diferentes idades.

Tabela 7: Teores de CAP residual da mistura nas diferentes idades.

\begin{tabular}{cccc}
\hline $\begin{array}{c}\text { IDADE } \\
(\text { dias })\end{array}$ & $\begin{array}{c}\text { TEOR DE CAP RESIDUAL } \\
(\%)\end{array}$ & $\begin{array}{c}\text { DP } \\
(\%)\end{array}$ \\
\hline 1 & 5,75 & & \\
7 & 5,05 & & \\
15 & 5,06 & 0,30 & 5,81 \\
30 & 5,20 & & \\
60 & 5,04 & & \\
\hline Média & 5,22 & & \\
\hline
\end{tabular}

É possível observar da Tabela 7 que os teores de CAP residual medidos para as diferentes idades de estocagem foram, em média, $8,75 \%$ superiores ao do teor de projeto da mistura (4,8\%). Essa diferença está relacionada, muito provavelmente, as características do método Rotarex [6] utilizado na extração do ligante asfáltico, que embora tenha apresentado pequena variabilidade nos resultados para cada idade testada, representada pelos baixos valores de DP e CV, tem como característica o carreamento de finos durante a lavagem da mistura com solvente, promovendo aumento do teor de CAP residual aferido, sendo, portanto, conforme GONÇALVES et al. [21], um método de baixa confiabilidade. Por outro lado, com base na Tabela 8, é possível afirmar que para todas as idades analisadas a granulometria do PMF se enquadrou adequadamente nos limites da faixa D estabelecidos pelo DNIT [14], comprovando que a amostragem realizada não comprometeu, neste aspecto, a qualidade dos resultados obtidos.

Estas constatações acerca do teor de ligante e granulometria da mistura comprovam que a variação observada nos resultados de estabilidade, fluência, Vv e RT ao longo do tempo não foram influenciadas por estes fatores, confirmando que o efeito do tempo de estocagem foi preponderante na perda progressiva da umidade da mistura, com consequente endurecimento do CAP presente na emulsão asfáltica antes da compactação.

Tabela 8: Composição granulométrica da mistura de agregados do PMF após extração do ligante asfáltico.

\begin{tabular}{|c|c|c|c|c|c|c|c|c|}
\hline \multicolumn{2}{|c|}{ PENEIRAS } & \multicolumn{5}{|c|}{ IDADE (DIAS) } & \multicolumn{2}{|c|}{ DNIT [14]- FAIXA D } \\
\hline \multirow{3}{*}{ Nome } & \multirow{3}{*}{$\begin{array}{c}\text { Abertura } \\
(\mathrm{mm})\end{array}$} & 1 & 7 & 15 & 30 & 60 & Inferior & Superior \\
\hline & & $\%$ & $\%$ & $\%$ & $\%$ & $\%$ & $\%$ & $\%$ \\
\hline & & Passante & Passante & Passante & Passante & Passante & Passante & Passante \\
\hline $1 "$ & 25,4 & 100 & 100 & 100 & 100 & 100 & 100 & 100 \\
\hline 3/4" & 19,0 & 100 & 100 & 100 & 100 & 100 & 100 & 100 \\
\hline $1 / 2^{\prime \prime}$ & 12,7 & 94,3 & 94,8 & 96,8 & 92,6 & 96,2 & 95 & 100 \\
\hline 3/8" & 9,5 & 70,2 & 66,9 & 72,9 & 74,6 & 65,6 & 45 & 80 \\
\hline \#4 & 4,8 & 38,2 & 34,6 & 37,7 & 30,5 & 30,2 & 25 & 45 \\
\hline$\# 10$ & 2,0 & 24,1 & 24,0 & 24,7 & 20,9 & 19,9 & 15 & 30 \\
\hline \#200 & 0,075 & 6,3 & 6,9 & 6,6 & 5,8 & 5,7 & 0 & 8 \\
\hline
\end{tabular}




\section{CONCLUSÕES}

A avaliação do comportamento mecânico da mistura permitiu constatar que a perda de umidade do PMF, provocada ao longo do tempo de estocagem, influenciou no comportamento mecânico do material. Dessa forma, o tempo de estocagem proporcionou queda da estabilidade, fluência e resistência a tração e aumento no volume de vazios da mistura. Entretanto, do ponto de vista dos limites estabelecidos pela especificação DNIT [14], apenas a estabilidade e fluência se mostraram determinantes quanto a viabilidade temporal da mistura produzida.

O ajuste matemático entre os quatro principais parâmetros analisados (Estabilidade, fluência, volume de vazios e RT) e o tempo de estocagem forneceram coeficientes de correlação $\left(\mathrm{R}^{2}\right)$ variados, desde valores mínimos de 0,75 para Vv (75 golpes) e 0,78 para fluência, até valores mais elevados de 0,96 para Vv (50 golpes) e 0,98 para Estabilidade. Estes valores de $\mathrm{R}^{2}$ indicam que a influência do tempo de estocagem nas características analisadas é consistente.

Portanto, com base nas exigências de Estabilidade e fluência [14] é possível estimar que o PMF produzido apresentou possibilidade de armazenamento pelo tempo máximo de 15 dias, para a energia de compactação de 50 golpes, e de 5 dias, para a energia de compactação de 75 golpes, atendendo aos limites estabelecidos pela especificação adotada [14], cabendo reiterar a importância da revisão da faixa estabelecida de volume de vazios da especificação DNIT [14], de forma a restringi-la, incentivando assim projetos de misturas mais estáveis no aspecto volumétrico.

\section{BIBLIOGRAFIA}

[1] ABEDA, Manual Básico de Emulsões Asfálticas. 2a. edição. Rio de Janeiro, 2010.

[2] ANUÁRIO CNT DO TRANSPORTE: ESTATÍSTICAS CONSOLIDADAS 2019, http://anuariodotransporte.cnt.org.br/2019/inicial. Acesso em 12/05/2020.

[3] BERNUCCI, L.B., MOTTA, L.M.G., CERATTI, J.A.P., et al. Pavimentação asfáltica: formação básica para engenheiros. 3a. ed. Rio de Janeiro: PETROBRAS: ABEDA, 2008.

[4] DIAZ. L.G., "Creep performance evaluation of Cold Mix Asphalt patching mixes", International Journal of Pavement Research and Technology, v. 9, n. 2, pp. 149-158, Mar. 2016.

[5] DAY, D., LANCASTER, I.M., MCKAY, D., "Emulsion cold mix asphalt in the UK: A decade of site and laboratory experience", Journal of Traffic and Transportation Engeneering, v. 6, n. 4, pp. 359-365, Aug. 2019.

[6] _ _. DNER-ME 53, Mistura betuminosa - porcentagem de betume, Rio de Janeiro, RJ, Brasil, 1994.

[7] _ _. DNER - ME 54, Equivalente de areia, Rio de Janeiro, RJ, Brasil, 1998.

[8] __. DNER-ME 81, Agregados - Determinação da absorção e da densidade de agregado graúdo, Rio de Janeiro, RJ, Brasil, 1998.

[9] _ _. DNER-ME 83, Agregados - Análise granulométrica, Rio de Janeiro, RJ, Brasil, 1998.

[10] _ _. DNER-ME 84, Agregado miúdo - determinação da densidade real, Rio de Janeiro, RJ, Brasil, 1998.

[11] _ . DNER-ME 107, Mistura betuminosa a frio, com emulsão asfáltica - ensaio Marshall, Rio de Janeiro, RJ, Brasil, 1994.

[12] _ . DNER-ME 117, Mistura betuminosa - determinação da densidade aparente, Rio de Janeiro, RJ, Brasil, 1994.

[13] _. . DNIT-ME 136, Determinação da resistência à tração por compressão diametral, Rio de Janeiro, RJ, Brasil, 2010.

[14] _. DNIT-ES 153, Pavimentação asfáltica - Pré-misturado a frio com emulsão catiônica convencional, Rio de Janeiro, RJ, Brasil, 2010.

[15] _ _. DNIT-EM 165, Emulsões asfálticas para pavimentação, Rio de Janeiro, RJ, Brasil, 2013.

[16] _ _. DNIT 719, Manual de pavimentação, Rio de Janeiro, RJ, Brasil, 2006.

[17] DONG, Q., YUAN, J., CHEN, X., et al "Reduction of moisture susceptibility of cold asphalt mixture with Portland cement and bentonite nanoclay additives", Journal of Cleaner Production, v. 176, pp. 320-328, Mar. 2019.

[18] DU, S., "Performance Characteristic of Cold Recycled Mixture with Asphalt Emulsion and Chemical Additives", Advances in Materials Science and Engineering, v. 2015, pp. 1-8, Nov. 2015. 
[19] FLORES, G., GLLEGO, J., MIRANDA, L., et al "Cold asphalt mix with emulsion and 100\% rap: Compaction energy and influence of emulsion and cement content", Construction and Building Materials, v. 250, Jul. 2020.

[20] GAO, L., NI, F., LUO, H., et al "Characterization of air voids in cold in-place recycling mixtures using X-ray computed tomography”, Construction and Building Materials, v. 84, pp. 429-436, Jun. 2015.

[21] GONÇALVES, B.C.S., PEREIRA, D.S., SPECHT, L.P., et al "Avaliação da centrifuga rotarex na determinação do teor de ligante e granulometria de diferentes concretos asfálticos”, v. 28, n. 3, pp. 75-90, Ago. 2020.

[22] GUATIMOSIM, F.V., VASCONCELOS, K.L., BERNUCCI, L.L.B., et al "Laboratory and field evaluation of cold recycling mixture with foamed asphalt", Road Materials and Pavement Design, v. 19, n. 2, pp. 385-399, 2018.

[23] LI, Z., HAO, P., LUI, H., et al "Investigation of early-stage strength for cold recycled asphalt mixture using foamed asphalt", Construction and Building Materials, v. 127, pp. 410-417, Nov. 2016.

[24] LIU, X., ZHOU, C., FENG, D., et al "Influence of moisture in aggregates on properties of cold-mixed resin asphalt mixture", Construction and Building Materials, v. 120, pp. 232-240, Sep. 2016.

[25] LIU, S., SHUKLA, A., NANDRA, T., "Technological, environmental and economic aspects of Asphalt recycling for road construction”, Renewable and Sustainable Energy Reviews, v. 75, pp. 879-893, Aug. 2017.

[26] RENDELIUS, P., ÖSTLUND, J., SOENEN, H., "Field experience of cold mix asphalt during 15 years", Road Materials and Pavement Design, v. 17, n. 1, pp. 223-242, 2016.

[27] SAADOON, T., GARCIA, A., GÓMEZ-MEIJIDE, B., "Dynamics of water evaporation in cold asphalt mixtures", Materials and Design, v.134, pp. 196-206, Nov. 2017.

[28] SANTANA, H. Manual de pré-misturado a frio. Rio de Janeiro: IBP, 1993.

[29] SANTANA, R.R., SANTOS, R., CAVALCANTE, E.H., et al "Estabilidade e adesividade de ligante asfalto modificado com blenda de borra oleosa de petróleo com borracha de pneu", Revista Matéria, v. 23, n. 1, Mar. 2018.

[30] SANTOS, K.P., LUCENA, A.E.F.L., LUCENA, L.C.F. , et al "Estudo da incorporação de argilas montmorilonitas em cimentos asfálticos de petróleo”, Revista Matéria, v. 20, n. 2, pp. 501-513, Mar. 2015.

[31] SENA NETO, P.G., AMORIM, E.F., INGUNZA, M.P.D., "Análises de dosagens de concreto asfáltico do tipo Pré Misturado a Frio (PMF) utilizando Resíduos da Construção e Demolição de obras (RCD)", Revista Matéria, v. 24, n. 4, Nov. 2019.

[32] TIEVES, L.P., GHISI, E.I., “Asphalt mixtures emission and energy consumption: A review”, Renewable and Sustainable Energy Reviews, v. 72, pp. 473-484, May. 2017.

[33] UNGER FILHO, W., KLINSKY, L.M.G., MOTTA, R., et al "Cold Recycled Asphalt Mixture using 100\% RAP with Emulsified Asphalt-Recycling Agent as a New Pavement Base Course", Advances in Materials Science and Engineering, v. 2020, Apr. 2020.

[34] XAVIER, M.F., FERREIRA, W.L.G., CASTELO BRANCO, V.T.F., “Avaliação do uso de cinzas de carvão mineral como melhorador de adesividade em misturas asfálticas", Revista Matéria, v. 25, n. 1, Abr. 2020.

\section{ORCID}

Wallace John Pereira Pedreira

Mario Sergio de Souza Almeida

André Iuri Sena de Carvalho

Francisco Gabriel Santos Silva https://orcid.org/0000-0002-3368-7414

https://orcid.org/0000-0002-0222-4804

https://orcid.org/0000-0001-7491-8541

https://orcid.org/0000-0003-0033-8127 